\title{
Fifty Years of Research in Balkan Endemic Nephropathy: Where Are We Now?
}

\author{
Vladisav Stefanović Momir Polenaković \\ Faculty of Medicine, Nis, Serbia; Macedonian Academy of Science and Arts, Skopje, Macedonia
}

\section{Key Words}

Balkan endemic nephropathy, etiology • Urothelial cancer •

Aristolochic acid · Ochratoxin A • Polycyclic aromatic

hydrocarbons

\begin{abstract}
Despite broad investigations into the possible role of genetic factors, environmental agents and immune mechanisms, the etiology of Balkan endemic nephropathy (BEN) is only partially understood. An increased incidence of upper urothelial cancer in patients with BEN and in populations from endemic settlements has been demonstrated. Genetic studies have landed support for genetic predisposition to BEN. The similarity of the morphological and clinical pattern of $B E N$ and Chinese herbs nephropathy has raised the possibility of a common etiologic agent, aristolochic acid (AA), described in 1969 by Ivić and confirmed by a recent study of AA-DNA adducts. Ochratoxin A (OTA) is studied extensively as the etiologic agent of BEN. Weathering of low-rank coals nearby the endemic villages produces water-soluble polycyclic aromatic hydrocarbons and aromatic amines, similar to metabolic products of acetaminophen, which has a causal relationship with analgesic nephropathy. AA is confirmed as the etiologic agent of BEN; however, it may not be the sole risk factor. More research is needed on the patterns of BEN over time and between different endemic places. Therefore, it is important to test etiological hypotheses in different en-
\end{abstract}

demic foci, preferably as a multicentric research. An international approach to solving the etiology of BEN is needed in the coming years. The geographic correlation and presence of AA-DNA adducts in both BEN and associated urothelial cancer support the hypothesis that these diseases share a common etiology.

Copyright $\odot 2009$ S. Karger AG, Basel

Balkan endemic nephropathy (BEN) is a chronic tubulointerstitial nephropathy with insidious onset and slow progression to terminal renal failure. Initially described in the 1950s, it affects people living in the alluvial plains along the tributaries of the Danube River in Bosnia and Herzegovina, Bulgaria, Croatia, Romania and Serbia [1]. An increased incidence of upper urothelial cancer (UUC) in patients with BEN and in populations from endemic settlements has been demonstrated [2]. We would like to give a survey of the recent studies and a prospect for future research.

\section{Epidemiological Characteristics of BEN}

The familial character of this disease was described in the first reports. BEN can affect several members of a household in one or more generations [1]. Within the same village, affected and spared households live in close

\section{KARGER}

Fax +4161306 1234 E-Mail karger@karger.ch www.karger.com

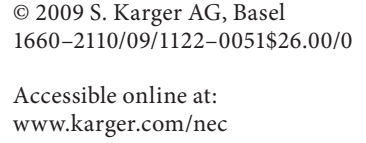

Prof. Vladisav Stefanović

Faculty of Medicine

Bul. Zorana Djindjica 81, 18000 Nis (Serbia)

Tel. +381 18570 029, Fax +381 18530127

E-Mail stefan@ni.ac.yu 
proximity. BEN occurs in some, but not all villages in the endemic area. Affected villages are sometimes separated from disease-free villages by only a few kilometers. Recently, we have made an analysis of the cumulative incidence of end-stage kidney disease patients on dialysis, from endemic, adjacent and control villages in the South Morava region in Serbia. In these adjacent villages, previously claimed as being non-endemic, there were two times more cases of end-stage kidney disease on dialysis than in control settlements, designated as sporadic cases of BEN.

The estimated prevalence of BEN in endemic areas ranges from 0.5 to $4.4 \%$ [3]. Subsequent reports, however, have suggested that the incidence of BEN may be decreasing [4]. A high incidence of BEN is still observed in the Kolubara River region in Serbia [5]. Since the early 1990s, the few new cases in one region in Serbia were only seen in previously affected families. Whereas 50 years ago BEN was diagnosed even in young adolescents, a diagnosis is now made in few people before they reach their $60 \mathrm{~s}$. In Croatia, the mean age of death associated with BEN was 45.1 years in the late 1950 s, and 69.2 years in the 1990s, which was similar to the life expectancy for the general population [6]. At the time of its discovery, BEN frequently led to death within 1 year or less, and a recent follow-up study showed that the mean yearly decrease of glomerular filtration rate in a series of biopsy samples was $2.74 \mathrm{ml} / \mathrm{min}$, implying that 30 years would be needed for an individual with normal kidney function (clearance $103.5 \pm 21.3 \mathrm{ml} / \mathrm{min} / 1.73 \mathrm{~m}^{2}$ ) to reach a stage of advanced renal failure (clearance $28.0 \pm 6.2 \mathrm{ml} / \mathrm{min} / 1.73$ $\mathrm{m}^{2}$ ) [7]. Consequently, although the total proportion of prevalent cases might not be different in some geographical foci, the incidence rates are now much lower all over the endemic regions.

\section{Genetic Predisposition to BEN}

A familial aggregation of BEN was described 50 years ago [1]. Development of BEN in emigrants from the endemic region, who left their native villages in early childhood and settled hundreds, sometimes thousands of miles away, supports the role of inheritance in the development of BEN [8]. A specific marker has been established on chromosome 3, 3q25 marker of susceptibility. Genome-wide scans have not been performed yet to identify SNP associated with BEN susceptibility. Certain BEN relatives carry chromosomal anomalies that have already been described in BEN patients, and it is proposed that they are at high risk for developing the disease [9]. On the other hand, evidence is presented that environmental rather than genetic factors play a decisive role in the etiopathogenesis of BEN. Two genetically different populations, natives and immigrants from the Ukraine who settled in the endemic regions near Slavonski Brod, Croatia, have been demonstrated to develop BEN [10].

\section{Environmentally Induced Disease}

Several cases of end-stage interstitial kidney disease have been reported in young women who were on a slimming regimen including Chinese herbs [11]. Aristolochic acid (AA) was isolated from several batches of pills, accidentally delivered as powder of Aristolochia fangchi, in place of non-toxic Stephania tetrandra. The similarity of the morphology and clinical features of Chinese herbs nephropathy and BEN has raised the possibility of a common etiologic agent - AA [12]. Some 40 years ago, AA was suggested as the etiologic agent of BEN. Ivić [13] found AA in flour obtained from wheat contaminated with seeds of Aristolochia clematitis in an endemic region. He conducted a survey of the geographical distribution of $A$. clematitis in the endemic area. This plant has both a nephrotoxic and cancerogenic action. Focal tubulointerstitial changes were observed in rabbits poisoned by giving them orally various amounts of flour made from ground dried Aristolochia seeds. These changes corresponded completely to the changes characteristic of BEN. Grollman et al. [14] recently confirmed the epidemiological and experimental data of Ivić [13], showing that: (i) DNA adducts derived from AA are present in renal tissue of patients with documented BEN, (ii) these adducts could be detected in transitional cell cancers, and (iii) A:T-T:A transversions dominate the $\mathrm{p} 53$ mutational spectrum in upper urinary tract malignancies. It is concluded that dietary exposure to AA is a significant risk factor for $\mathrm{BEN}$ and its attendant transitional cell cancer. Rodent models of AAN may be used to study biotransformation of AA and repair of AL-DNA adducts and, importantly, to validate the use of AL-DNA adducts as biomarkers of disease [15]. The murine model will be particularly useful for determining genetic susceptibility to AAN and, by implication, to BEN [16].

Feder et al. [17] found that endemic settlements are located in the vicinity of Pliocene age lignites. Weathering of the low-rank coals could generate complex mixtures of water-soluble hydrocarbons which are present in the drinking water of the shallow farm wells, e.g. naph- 
thylamine, aniline, anthracene, pyrene. Many of these compounds are known to be carcinogenic and could also cause urothelial cancer. Ochratoxin A (OTA) is a mycotoxin demonstrated to be responsible for porcine nephropathy in northern Europe. Porcine nephropathy is primarily a tubulointerstitial disease similar to BEN in many ways, suggesting a common causal relationship. The most pronounced food-borne exposure to OTA has been found in the area in Croatia where BEN is prevalent [18]. The associated nephrotoxicity and carcinogenicity of OTA, recently described, make this hypothesis particularly attractive. However, to date there is no evidence that OTA is responsible for any known kidney disease in humans. A comprehensive presentation of the mycotoxin argument was recently published by Pfohl-Leszkowicz et al. [19].

The pathway for exposure to OTA is well defined and there is evidence that humans have ingested OTA [20]. Factors causing differential exposure to OTA and how OTA is implicated in BEN are not defined. Although there is evidence of human exposure to AA and that its effects are consistent with BEN, a pathway for exposure to AA has been suggested but not demonstrated. Factors causing differential exposure to AA are not known. Exposure analysis results suggest that neither OTA nor AA can be firmly linked to BEN. However, this approach suggests future research directions that could provide critical evidence on exposure, which when linked with findings from the health sciences, may be able to demonstrate the cause of this disease and provide a basis for effective public health intervention strategies. One of the key unknowns for both agents is how differential exposure can occur [20]. Although questioned by Grollman and Jelaković [21], nobody has really ruled out the etiologic role of mycotoxins (epigenetic effect) and coal leachates $[22,23]$.

\section{Clinical and Morphologic Characteristics}

BEN is characterized by tubular dysfunction, predominantly affecting the proximal tubule. Glucosuria and aminoaciduria have been reported. A tubular type of proteinuria was found to occur in BEN before routine tests for proteinuria become positive. There is an increased $\beta_{2-}$ microglobulin excretion in patients with BEN, their clinically healthy relatives, adult offspring of families with $\mathrm{BEN}$, as well as in children from these families [24, 25]. $\mathrm{BEN}$ is characterized by diffuse cortical interstitial fibrosis, which is hypocellular in the majority of cases, and by tubular atrophy with both features decreasing from the outer to the inner cortex [26]. At early stages the lesions are focal and associated with interstitial edema as well as proximal tubule epithelial cell degeneration.

\section{Diagnosis of BEN}

Diagnosis of BEN is made in inhabitants from endemic settlements using diagnostic criteria proposed by an international panel [27]: (1) epidemiologic criteria; (2) demonstration of the glomerular filtration rate decrease, proteinuria, generally $<1 \mathrm{~g} / 24 \mathrm{~h}$, microalbuminuria, tubular markers (increased urinary excretion of $\beta_{2}$-microglobulin or $\alpha_{1}$-microglobulin), and (3) exclusion of other known kidney diseases.

\section{Screening of BEN}

Despite the availability of improved medical therapy to slow the progression of nephropathy, true epidemics of end-stage kidney disease due to BEN can be observed. $\mathrm{BEN}$ is still the major problem in several endemic regions in Bosnia, Croatia and Serbia. Many patients are not diagnosed until the late stages of disease, as early kidney disease may be asymptomatic. Ideally all adults in endemic settlements should be routinely screened for evidence of early BEN and associated risk factors [27]. Since BEN areas are relatively small and the cost of screening does not exceed $1-2 \%$ of the treatment of end-stage BEN and UUC-associated BEN, screening of endemic families is cost-effective [28]. Healthcare institutions in BEN areas are well developed and an integrated, well-developed program could lead to the eradication of BEN. Members of a working party for the management of chronic kidney disease have identified several recommendations for the screening of patients at risk of chronic kidney disease [29]. These could be used for the screening of patients at risk of BEN.

\section{How to Screen for BEN?}

Take a short history including family history, and measure blood pressure. Use a dipstick (untimed spot urine sample) for proteinuria, albuminuria, WBC and RBC: (1) If positive for proteinuria: measure total protein to creatinine ratio in an untimed spot urine sample; if positive for albuminuria: measure albumin to creatinine ratio in an untimed spot urine sample, and if positive for WBC or RBC: perform a sediment analysis in an untimed spot 
urine sample. (2) The determination of $\beta_{2}$-microglobulin in urine is a useful tool in the screening procedure of tubular dysfunction in BEN. $\alpha_{1}$-Microglobulin, which is much more stable than $\beta_{2}$-microglobulin in urine, has also been described as a useful screening tool in BEN. (3) Estimate creatinine clearance from serum creatinine using the Cockcroft-Gault equation or MDRD study equation. (4) Renal ultrasonography is usually needed.

\section{How Often Should Screening Be Performed?}

(1) If screening is negative: every 1-3 years, depending on risk factors. (2) If abnormality is evidenced at screening: perform diagnostic and therapeutic work-up.

\section{Detection, Treatment and Prevention of BEN}

Diagnostic criteria for BEN have been re-evaluated by an international panel of investigators, and a meeting of BEN center directors was convened for this purpose last year in Croatia [28]. A screening procedure in endemic settlements should be associated with diagnostic and therapeutic workup. The evaluation and treatment of patients with BEN requires understanding of diagnosis, comorbid conditions, severity of disease, complications of disease, and risks for loss of kidney function, and cardiovascular disease. A clinical action plan should be developed for each patient, based on the stage of disease as defined by the K/DOQI CKD classification [29]. Treatment of BEN is similar to that of all chronic interstitial nephropathies: detection and treatment of potentially reversible aggravating factors, limited protein intake from stage 3, and kidney replacement therapy. Hypertension, if present, should be treated with angiotensin-converting enzyme inhibitors. Longer survival on renal replacement therapy is associated with the increased risk of developing renal pelvis, ureter, and urinary bladder tumors.

Understanding the etiology of BEN should be followed with etiological treatment and prevention [27, 30]. Primary prevention is the major goal in BEN. In regions where AA is the culprit of disease, public health authorities should take immediate measures to reduce the potential for dietary exposure of residents to Aristolochia.

\section{Urothelial Cancer}

The increased frequency of urothelial cancer in populations of endemic villages was described in the first reports on BEN in both Bulgaria and former Yugoslavia [see 2]. A geographic correlation between UUC and BEN was established in both Yugoslavia and Bulgaria. A recent survey of UUC in the South Morava River basin and its tributaries where BEN is endemic revealed an increased frequency of not only renal pelvis and ureter tumors but also of urinary bladder tumors [31]. Familial clustering was also noted. The incidence of UUC and bladder tumors associated with BEN in the region of South Morava River in Serbia in the last 10-year period (1989-1998) was markedly decreased. Compared to the period from 1969 to 1988 , UUC in endemic settlements was 11.2 times more frequent than in non-endemic settlements, but was 57.1 times more frequent in the period from 1969 to 1988 [32].

The geographic correlation and presence of AA-DNA adducts in both BEN and associated urothelial cancer support the speculation that these diseases share a common etiology.

\section{Conclusion}

Recent studies in BEN and associated UC are the major step in understanding the etiology and preparing an etiologic approach for diagnosis, prevention and treatment. AA is confirmed as the etiologic agent of BEN; however, it may not be the sole risk factor. More research is needed on the patterns of BEN over time and between different endemic places. Therefore, it is important to test etiological hypotheses in different endemic foci, preferably as a multicentric research. An international approach to solving the etiology of $\mathrm{BEN}$ is needed in the coming years. It is also time to reevaluate other chronic, slowly progressive tubulointerstitial nephropathies of unknown etiology, diagnosed elsewhere in the world, and to search for possible etiological similarities with BEN.

After 50 years of investigation, BEN and associated UUC are still full of secrets with more questions than answers, but fortunately with less frequent and less important health problems. However, with this trend of decreasing incidence, we have to wait at least one or two decades more to follow up the problem before closing it. As we predicted in 1991, with the etiologic diagnosis it will be possible to detect BEN and associated UUC beyond the Balkans where sporadic cases occur [33].

\section{Acknowledgment}

This work was supported by grant No. 145004 from the Ministry of Science and Technological Development of Serbia. 


\section{References}

1 Polenaković M, Stefanović V: Balkan nephropathy; in Cameron JS, Davison AM, Grunfeld JP, Kerr D, Ritz E (eds): Oxford Textbook of Clinical Nephrology, ed 1. Oxford, Oxford University Press, 1992, pp 857866.

-2 Stefanović V, Radovanović Z: Balkan endemic nephropathy and associated urothelial cancer. Nat Clin Pract Urol 2008;5:105111.

-3 Ceović S, Hrabar A, Saric M: Epidemiology of Balkan endemic nephropathy. Food Chem Toxicol 1992;30:183-188.

-4 Cukuranović R, Petrović B, Cukuranović Z, Stefanović V: Balkan endemic nephropathy: a decreasing incidence of the disease. Patho Biol 2000;48:558-561.

5 Bukvić D, Janković S, Arsenović A, Djukanović L: Prevalence of Balkan endemic nephropathy has not changed since 1971 in the Kolubara region in Serbia. Kidney Blood Press Res 2007;30:117-123.

-6 Miletic-Medved M, Domijan AM, Peraica M: Recent data on endemic nephropathy and related urothelial tumors in Croatia. Wien Klin Wochenschr 2005;117:604-609.

-7 Cukuranović R, Savić V, Stefanović N, Stefanović V: Progression of kidney damage in Balkan endemic nephropathy: a 15-year follow-up of patients with kidney biopsy examination. Ren Fail 2005;27:701-706.

-8 Nikolic J, Djokic M, Ignjatović I, Stefanović V: Upper urothelial tumors in emigrants from Balkan endemic nephropathy areas in Serbia. Urol Int 2006:77:240-244.

$\checkmark 9$ Toncheva D, Dimitrov T: Genetic predispo sition to Balkan endemic nephropathy. Nephron 1996;72:564-569.

10 Ceović S, Hrabar A, Radonic M: An etiological approach to Balkan endemic nephropathy based on the investigation of two genetically different populations. Nephron 1985; 40:175-179.

-11 Vanherweghen JL, Depierreux M, Tielmans C, Abramowicz D, Dratawa M, Jadoul M, Richard C, Vandervelde D, Verbeelen D, Vanhaelen Fastre R, Vanhaelen M: Rapidly progressive interstitial renal fibrosis in young women: association with slimming regimen including Chinese herbs. Lancet 1993;341:387-391.
12 Cosyns JP, Jadoul M, Squifflet JP, De Plaen JF, Ferluga D, van Ypersele de Strihou C: Chinese herbs nephropathy: a clue to Balkan endemic nephropathy. Kidney Int 1994;45: 1680-1688.

13 Ivić M: The problem of etiology of endemic nephropathy. Lijec Vjes 1969;91:1278-1281.

14 Grollman AP, Shibutani S, Moriya M, Miller F, Wu L, Moll U, Suzuki N, Fernandes A, Rosenquist T, Medverec Z, Jakovina K, Brdar B, Slade N, Turesky R, Goodenough AK, Vukelic M, Jelaković B: Aristolochic acid and the etiology of endemic (Balkan) nephropathy. Proc Natl Acad Sci USA 2007; 104:1212912134.

15 Wogan GN, Hecht SS, Flton JS, Coney AH, Loeb LA: Environmental and chemical carcinogenesis. Semin Can Biol 2004;14:473486.

16 Shibutani S, Dong H, Suzuki N, Ueda S, Miller F, Grollman AP: Selective toxicity of aristolochic acid I and II. Drug Metab Dispos 2007;35:1217-1222.

17 Feder GL, Radovanović Z, Finkelman RB: Relationship between weathered coal deposits and the etiology of Balkan endemic nephropathy. Kidney Int 1991;40(suppl 34):S9S11.

18 Pfohl-Leszkowicz A, Tozlovanu M, Manderville R, Peraica M, Castegnaro M, Stefanović $\mathrm{V}$ : New molecular and field evidences for the implication of mycotoxins but not aristolochic acid in human nephropathy and urinary tract tumor. Mol Nutr Food Res 2007;51: 1131-1146.

19 Pfohl-Leszkowicz A, Petkova-Bocharova T, Chernozemsky IN, Castegnaro M: Balkan endemic nephropathy and associated urinary tract tumours: a review on aetiological causes and the potential role of mycotoxins. Food Addit Contam 2002;19:282-302.

20 Long DT, Voice T: Role of exposure analysis in solving the mystery of Balkan endemic nephropathy. Croat Med J 2007;48:300-311.

21 Grollman AP, Jelaković B: Role of environmental toxins in endemic (Balkan) nephropathy. J Am Soc Nephrol 2007;18:2817-2823.

22 Bamias G, Boletis J: Balkan nephropathy: evolution of our knowledge. Am J Kidney Dis 2008;52:606-616.

-23 Schiller A, Gusbeth-Tatomir P, Pavlović N, Ferluga D, Spasovski G, Cović A: Balkan endemic nephropathy; a still unsolved puzzle. J Nephrol 2008;21:673-680.
24 Stefanović V, Mitic-Zlatković M, Cukuranović R, Miljković P, Pavlović NM, Vlahović P: Beta-2-Microglobulin in patients with Balkan nephropathy and in healthy members of their families. Kidney Int 1991; 40(suppl 34):S21-S26.

25 Dimitrov P, Tsolova S, Georgieva R, Bozhilova D, Simeonov V, Bonev A, Karmaus W: Clinical markers in adult offspring of families with and without Balkan endemic nephropathy. Kidney Int 2006;69:723-729.

26 Stefanović V, Cosyns JP: Balkan Nephropathy; in Davison AM, Cameron JS, Grunfeld JP, Ponticelli C, Van Ypersele C, Ritz E, Winearls CG (eds): Oxford Textbook of Clinical Nephrology, ed 3. Oxford, Oxford University Press, 2004, pp 1095-1102.

27 Stefanović V, Jelaković B, Cukuranović R, Bukvić D, Nikolic J, Lukic L, Gluhovschi G, Toncheva D, Polenaković M, Cosyns JP: Diagnostic criteria for Balkan endemic nephropathy: proposal by an international panel. Ren Fail 2007;29:867-880.

28 Arsenović A, Bukvić D, Trbojević S, Maric I, Djukanović L: Detection of renal dysfunction in family members of patients with Balkan endemic nephropathy. Am J Nephrol 2005;25:50-54

29 National Kidney Foundation: K/DOQI clinical practice guidelines for chronic kidney disease: evaluation, classification, and stratification. Kidney Disease Outcome Quality Initiative. Am J Kidney Dis 2002;39(suppl 1): S1-S266.

30 Bello AK, Nwankwo E, El Nahas M: Prevention of chronic kidney disease: a global challenge. Kidney Int 2005;68(suppl 98):S11S17.

31 Cukuranović R, Ignjatović M, Stefanović V: Urinary tract tumors and Balkan nephropathy in the South Morava River basin. Kidney Int 1991;40(suppl 34):S80-S84.

32 Marković N, Ignjatović I, Cukuranović R, Petrović B, Kocic B, Stefanović V: Decreasing incidence of urothelial cancer in a Balkan endemic nephropathy region in Serbia. A surgery-based study from 1969 to 1998. Pathol Biol (Paris) 2005;53:26-29.

33 Stefanović V, Polenaković M: Editorial: Balkan nephropathy. Kidney disease beyond the Balkans? Am J Nephrol 1991;11:1-11. 


\section{Editorial Comment}

M. El Nahas, Sheffield

This review by two world experts in the field of Balkan endemic nephropathy (BEN) brings the reader up to date with developments in the study of this intriguing geographical nephrological condition. It draws attention to the link between BEN, the associated uroepithelial cancer and toxins such as aristolochic acid (AA). Patients suffering from BEN may have been exposed to food crops, and/or flour derived from wheat contaminated with Aristolochia clematitis which contains high levels of AA. AA has also been implicated in the nephrotoxicity of Chinese herbal remedies. In Asian countries, the complexity of processing of Chinese herbal remedies and the common substitution of botanical products by AA-containing herbs represents a major risk for AA-associated nephropathy (AAN). Consequently, the incidence of AAN is probably much higher than initially thought, especially in Asia and the Balkans. Debelle et al. in another review article on AAN pointed to the Food and Drug Administration's warnings concerning the safety of herbal remedies containing AA including many sold via the Internet [Debelle FD, Vanherweghem JL, Nortier JL: Aristolochic acid nephropathy: a worldwide problem. Kidney Int 2008; 74:158-169]. 